Check for updates

Cite this: RSC Adv., 2019, 9, 17967

Received 18th May 2019

Accepted 23rd May 2019

DOI: $10.1039 / c 9 r a 03743 h$

rsc.li/rsc-advances

\section{A novel fabrication method of copper-reduced graphene oxide composites with highly aligned reduced graphene oxide and highly anisotropic thermal conductivity}

\author{
Faisal Nazeer, ${ }^{\text {ab }}$ Zhuang Ma, ${ }^{\text {ab }}$ Yitong Xie, ${ }^{\text {ab }}$ Lihong Gao, (D)*ab Abdul Malik, ${ }^{\text {ab }}$ \\ Muhammad Abubaker Khan, ${ }^{\text {ab }}$ Fuchi Wang ${ }^{\mathrm{ab}}$ and Hezhang Li ${ }^{\mathrm{ab}}$
}

Recently, metals with graphene and graphene oxide have been extensively used to enhance the mechanical and anisotropic thermal properties of composites. A novel facile fabrication approach of layer by layer selfassembly followed by hot press sintering was adopted to make copper-reduced graphene oxide composites. The microstructure and heat dissipation properties of pure copper and copper-reduced graphene oxide composites were analyzed with the help of SEM and continuous laser machine analysis. Thermal diffusivity of pure copper and copper-reduced graphene oxide composites was examined in different directions to measure the anisotropic thermal properties by using different volumetric percentages of reduced graphene oxide in the composites. Extraordinarily high anisotropic thermal conductivity of the copper-reduced graphene oxide composites was obtained at a very low concentration of 0.8 vol\% reduced graphene oxide, with the difference between the thermal conductivity in-plane and through-plane being a factor of 8.82. Laser test results confirmed the highly anisotropic behavior of our copper-reduced graphene oxide composite with the remarkable property of heat dissipation. The three point bending test was also performed to check the flexural strength of the composites. At 0.6 vol\% rGO, the flexural strength was noted ( $127 \mathrm{MPa})$, and it is $22 \%$ higher than that of pure sintered $\mathrm{Cu}$. The high value of anisotropic thermal conductivity and higher flexural strength exhibited by the copper-reduced graphene oxide composite produced using a simple two-step fabrication method give us new hope to use these materials as heat sinks in thermal packaging systems.

\section{Introduction}

Recent advancement in the miniaturization of electronic industry led to intensely dense packages, which causes an impressive increase in the amount of heat generated per unit volume. It is necessary to improve the miniaturization of electronic equipment for the advancement of heat dissipation technology. We need to make materials with properties that are properly designed and controlled, which fulfil the requirements of the heat dissipation industry. For this purpose, we would like to improve the anisotropic thermal properties of the materials that can be used in the field of thermal management systems as heat sinks. Most metals have good thermal dissipation properties compared with other materials (semi-conductors, polymers), so metals are the best choice for this purpose. Copper $(\mathrm{Cu})$ has good values of thermal conductivity (TC), but its thermal conductivity values in different

${ }^{a}$ School of Materials Science and Engineering, Beijing Institute of Technology, Beijing 100081, China. E-mail: gaolihong@bit.edu.cn; Fax: +86-10-68911144-865; Tel: +8610-68911144-866

${ }^{b}$ National Key Laboratory of Science and Technology on Materials under Shock and Impact, Beijing 100081, China directions, i.e., anisotropic thermal conductivity, differ little. To enhance the anisotropic thermal conductivity property of $\mathrm{Cu}$, a few researchers used different fillers (reinforcement) such as graphite, graphene oxide and graphene. ${ }^{\mathbf{1 - 1 5}}$

Graphene has extraordinarily high values of anisotropic thermal conductivity in-plane $\left(4000-5000 \mathrm{~W} \mathrm{~m}^{-1} \mathrm{~K}^{-1}\right)^{16}$ and through-plane $\left(5-20 \mathrm{~W} \mathrm{~m}^{-1} \mathrm{~K}^{-1}\right),{ }^{17}$ so it is the best choice as a filler in a metal. Most of the researchers used graphene and its derivatives with metals and polymers. ${ }^{17-23}$ Boden et al. ${ }^{13}$ prepared $\mathrm{Cu}$-graphene composites by using the powder metallurgy technique (ball milling + SPS). Their best sample showed an anisotropic thermal conductivity in-plane $\left(292 \mathrm{~W} \mathrm{~m}^{-1} \mathrm{~K}^{-1}\right)$ larger than through-plane by a factor of only 3 . Some other researchers used pressure assisted techniques to improve the anisotropic thermal conductivity but, unfortunately, the results were frustrating. Fanyan Chen et al. ${ }^{24}$ adopted a (molecular level mixing + SPS) technique to align the graphene content within the $\mathrm{Cu}$ matrix. Even at $4 \mathrm{vol} \%$ graphene, the results of anisotropic thermal conductivity are not as good as expected. The difference between the in-plane and through-plane conductivity was a factor of 1.5. Graphene was not aligned properly by using these conventional 
methods of mixing. Cao et $a .^{25}$ recently adopted a bio-inspired strategy to develop highly aligned graphene in the $\mathrm{Cu}$ matrix, and yield strength and elastic modulus increased significantly by $177 \%$ and $25 \%$ compared with pure $\mathrm{Cu}$, respectively. However, they did not discuss the thermal properties of their composites.

We need to find an efficient way for the fabrication of coppergraphene composites with a high degree of alignment of graphene and to improve the anisotropic thermal conductivity of the composites. However, the study of graphene alignment in $\mathrm{Cu}$ composites is still rare. ${ }^{13}$ Most of the researchers used different techniques such as molecular level mixing, ${ }^{26,27}$ in situ chemical vapour deposition, ${ }^{28-30}$ flake powder metallurgy, ${ }^{26}$ bioinspired preform impregnation $^{31}$ and pulse reverse electrode. ${ }^{32}$ Unfortunately, they were not able to achieve a high value of anisotropic thermal conductivity even by using a very high concentration of fillers. Our previous results obtained by using the conventional method of powder metallurgy at a high percentage of $5 \mathrm{wt} \%$ rGO in a Cu-rGO composite showed a TC ratio difference of in-plane to through-plane of just 3.46. This result is not good enough, so we consider a layer by layer structure to enhance the ratio of TC. On the other hand, $\mathrm{Cu}$-graphene films have also been examined, such as graphene-Cu-graphene heterogeneous film, ${ }^{9}$ RGO-graphene film ${ }^{33}$ and nitrogen doped graphene film. ${ }^{34}$ Although these films had high values of thermal conductivity and anisotropic thermal conductivity, there are many drawbacks of these composite films, such as they cannot be used on an industrial scale, because they can hardly be machined to the required parts with complex 3D shape limitations.

In this paper, we adopted an efficient route to achieve a high degree of alignment of reduced graphene oxide (rGO) within a copper $(\mathrm{Cu})$ matrix by using a simple two-step fabrication method of layer by layer self-assembly followed by hot press sintering. It was found that the composites had highly aligned rGO and a well packed laminated structure, leading to an extraordinarily high anisotropic thermal conductivity. Laser irradiation test confirmed the highly anisotropic structure of the composites and enormous ability to dissipate the heat compared with pure $\mathrm{Cu}$. This facile fabrication method and extraordinarily high values of anisotropic thermal conductivity may open up new doors for the development of $\mathrm{Cu}-\mathrm{rGO}$ composites for thermal management applications.

\section{Experimental}

\subsection{Synthesis of graphene oxide (GO)}

Copper substrate of thickness $0.001 \mathrm{~cm}$ and natural graphite powder (purity $>99.99 \%$, mesh size $1000 \mu \mathrm{m}$ ) were provided by Beijing Xing Rong Yuan Technology Co., LTD.

GO was synthesized by a modified hummer's method ${ }^{35}$ with a mesh size of $1000 \mu \mathrm{m}$ of natural graphite flake powder. Initially, $25 \mathrm{ml}$ (90\%) of concentrated $\mathrm{H}_{2} \mathrm{SO}_{4}$ was heated at $90{ }^{\circ} \mathrm{C}$, then $5 \mathrm{~g}$ of each of $\mathrm{K}_{2} \mathrm{~S}_{2} \mathrm{O}_{8}, \mathrm{P}_{2} \mathrm{O}_{5}$ and $6.2 \mathrm{~g}$ graphite was added keeping temperature at $80{ }^{\circ} \mathrm{C}$ for $4.5 \mathrm{~h}$. This solution was then treated with $200 \mathrm{ml}$ of $\mathrm{H}_{2} \mathrm{SO}_{4}$ and $30 \mathrm{~g}$ of $\mathrm{KMnO}_{4}$ at a temperature $<10{ }^{\circ} \mathrm{C}$ for $3 \mathrm{~h}$ under constant magnetic stirring. Finally, the solution was washed with $25 \mathrm{ml}$ of $\mathrm{H}_{2} \mathrm{O}_{2}(30 \%)$ and HCL (5 wt\%) 3 times.

\subsection{Fabrication of $\mathrm{Cu}-\mathrm{rGO}$ composites}

Copper substrates were cut into pieces keeping the diameter of each substrate at $2.5 \mathrm{~cm}$. Cu substrate pieces were placed on a square glass $(\varphi=24 \times 24 \mathrm{~cm})$ and GO $(0.4,0.6$ and 0.8 vol\%) was deposited on these $\mathrm{Cu}$ substrates by using ethyl alcohol as a solvent. GO deposited on $\mathrm{Cu}$ substrates was left at room temperature for $48 \mathrm{~h}$ for natural drying and ethyl alcohol evaporated. Cu-rGO composites formed in a layer by layer manner were sintered by using the hot press sintering machine for $3 \mathrm{~h}$ keeping the temperature at $950{ }^{\circ} \mathrm{C}$ and pressure at $35 \mathrm{MPa}$ under an $\mathrm{Ar}^{+}$gas atmosphere. During the sintering process, GO was reduced to rGO. Pure $\mathrm{Cu}$ substrates were also sintered under the same conditions for comparison. The whole process of composite preparation is illustrated in Fig. 1.

\subsection{Characterization}

The density of the bulk composites was measured by using the Archimedes principle.

$$
\frac{1}{\rho_{\mathrm{C}}}=\frac{M_{\mathrm{Cu}}}{D_{\mathrm{Cu}}}+\frac{M_{\mathrm{rGO}}}{D_{\mathrm{rGO}}}
$$

$\rho_{\mathrm{C}}$ is the density of the composite, $M_{\mathrm{Cu}}$ and $M_{\mathrm{rGO}}$ are the mass of copper and mass of reduced graphene oxide, while $D_{\mathrm{Cu}}$ and $D_{\mathrm{rGO}}$ are the density of copper and density of reduced graphene oxide, $8.96 \mathrm{~g} \mathrm{~cm}^{-3}$ and $2.25 \mathrm{~g} \mathrm{~cm}^{-3}$, respectively. Disorder in rGO was examined by using the Raman spectroscopy technique with an $\mathrm{Ar}^{+}$laser wavelength of $532 \mathrm{~nm}$ (inVia-Reflex, Britain).

The microstructure of the bulk composite was investigated by using scanning electron microscopy (SEM, Hitachi S-4800, Japan). Thermal diffusivity of the composite was measured in both parallel and perpendicular directions by using a NETZSCH Laser Flash Analysis 467 machine at room temperature. The thermal conductivity of the composites was calculated by using the formula $K=\alpha C_{\mathrm{p}} \rho$, where $\alpha$ is the thermal diffusivity and $C_{\mathrm{p}}$ is the specific heat capacity calculated by using the simple rule of a mixture of composites, $C_{\mathrm{p}}$ (mixture $)=\left(\frac{m_{1}}{m_{\text {mixture }}}\right) C_{\mathrm{p} 1}+\left(\frac{m_{2}}{m_{\text {mixture }}}\right) C_{\mathrm{p} 2}$, where $C_{\mathrm{p}}$ is the heat capacity, $m_{1}$ and $m_{2}$ are the mass of $\mathrm{Cu}$ and $\mathrm{rGO}, C_{\mathrm{p} 1}$ and $C_{\mathrm{p} 2}$ are the specific heat capacity of $\mathrm{Cu}$ and $\mathrm{rGO}$, while $\rho$ is the density of the composites. The same sample that have a thickness of $2 \mathrm{~mm}$ and diameter of $25 \mathrm{~mm}$ were used to determine the in-plane and through-plane thermal conductivity of pure $\mathrm{Cu}$ and the $\mathrm{Cu}-\mathrm{rGO}$ composites, as shown in Fig. 2. Laser irradiation test was performed with a Nd:YAG continuous laser machine with $1070 \mathrm{~nm}$ wavelength by using laser power at $1000 \mathrm{~W} \mathrm{~cm}^{-2}$ and irradiation time was set to $5 \mathrm{~s}$. The flexural strength of $\mathrm{Cu}$ and the $\mathrm{Cu}-\mathrm{rGO}$ composites of dimensions $2 \mathrm{~mm}$

$\times 4 \mathrm{~mm} \times 20 \mathrm{~mm}$ was measured by the three-point bending method with a crosshead speed of $0.5 \mathrm{~mm} \mathrm{~min}^{-1}$ and span of $30 \mathrm{~mm}$ at room temperature using an electromechanical universal testing machine (INSTRON-5566, Norwood, America). Three consecutive specimens were treated to gain average values of flexural strength. 


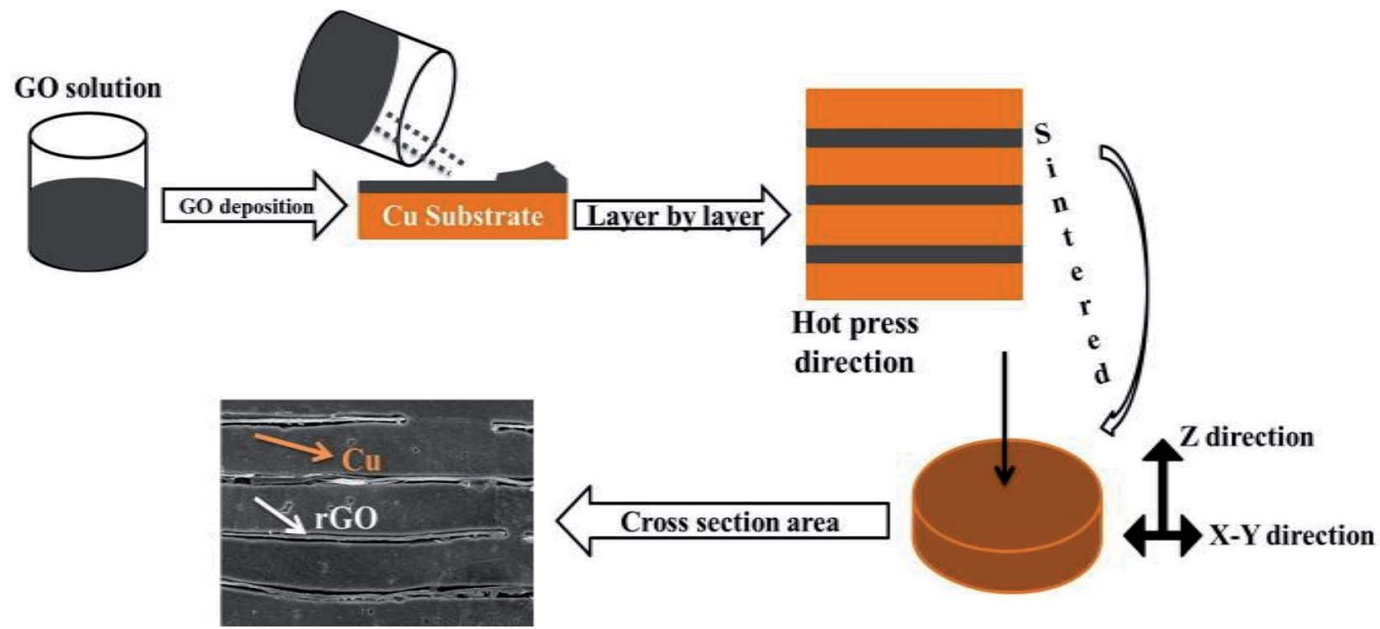

Fig. 1 Schematic diagram of Cu-rGO composites formed by the layer by layer method.
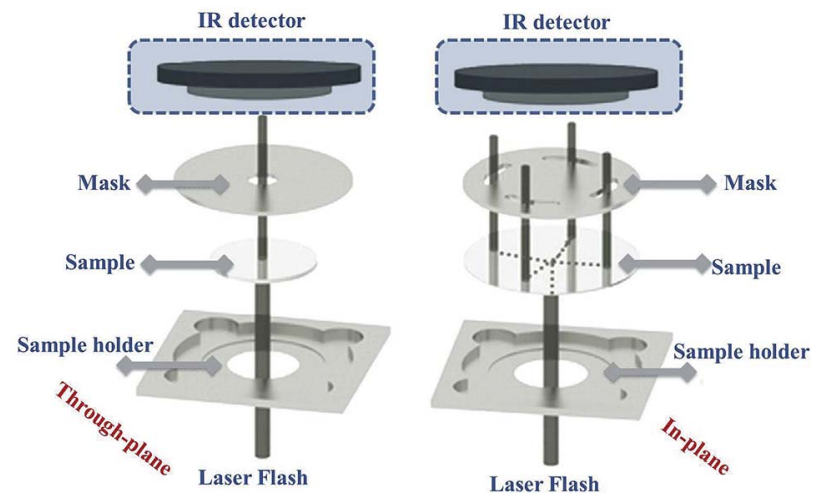

Fig. 2 Schematic illustration of sample holders used for the measurement of the anisotropic thermal diffusion coefficient $(\alpha)$.

\section{Results and discussion}

\subsection{Raw powder and rGO characterization}

A SEM image of graphite powder is shown in Fig. 3a. The shape of the graphite powder particles is irregular. The XRD pattern of graphite powder is shown in Fig. 3b. There are two obvious peaks of graphite at an angle $2 \theta=26.5^{\circ}$ and $54.6^{\circ}$ corresponding to the (002) and (004) crystal planes of the graphite flakes (JCDPS no. 41-1487), respectively. The $d$-spacing of the asreceived graphite is $3.367 \AA$, which is approximately equal to the $d$-spacing of single crystal graphite, $3.353 \AA$. The narrow peaks and $d$-spacing values indicate that graphite has a highly graphitic nature, which is good for the thermal conductivity in the basal plane. ${ }^{36}$

A SEM image and the XRD pattern of rGO powder are exhibited in Fig. 4. The morphology of rGO is flake-like, as shown in Fig. 3a. We observed a strong peak from rGO at an angle $2 \theta=26.6^{\circ}$ corresponding to the (003) crystal plane (JCDPS no. 26-1079). Mostly rGO peak signals were observed at the same angle, as shown in the inset of Fig. 4 b. Raman analysis of the reduced graphene oxide powder shows the presence of $I_{\mathrm{D}}$ and $I_{\mathrm{G}}$ peaks in Fig. 4c. The typical $\mathrm{D}$ band value of carbonbased materials lies between $1280 \mathrm{~cm}^{-1}$ and $1450 \mathrm{~cm}^{-1}$ and the $\mathrm{G}$ band values are about $1580 \mathrm{~cm}^{-1}$. The $\mathrm{D}$ to $\mathrm{G}$ band ratio of graphene oxide is $I_{\mathrm{D}} / I_{\mathrm{G}}=0.87$. Higher values of $\mathrm{D}$ to $\mathrm{G}$ band ratio clearly indicate the presence of oxygen functional groups and broken aromatic rings.

\subsection{Microstructure analysis of $\mathrm{Cu}-\mathrm{rGO}$ composites}

Cross-sectional SEM images of the $\mathrm{Cu}-\mathrm{rGO}$ composites are demonstrated in Fig. 5. Interfacial bonding between the $\mathrm{Cu}-$
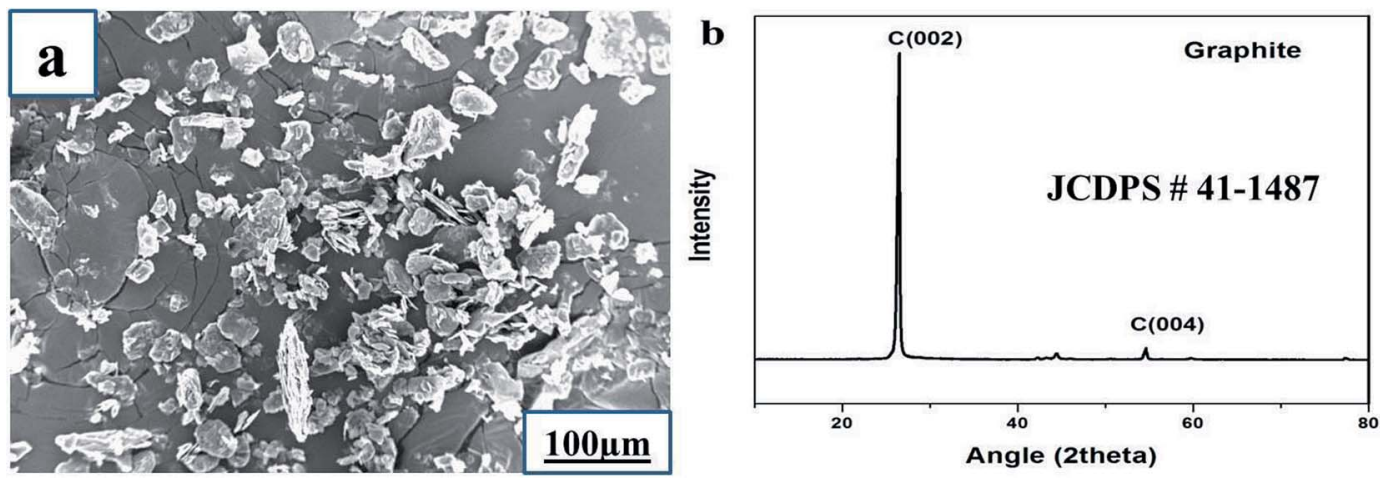

Fig. 3 Graphite powder: (a) SEM image and (b) XRD pattern. 

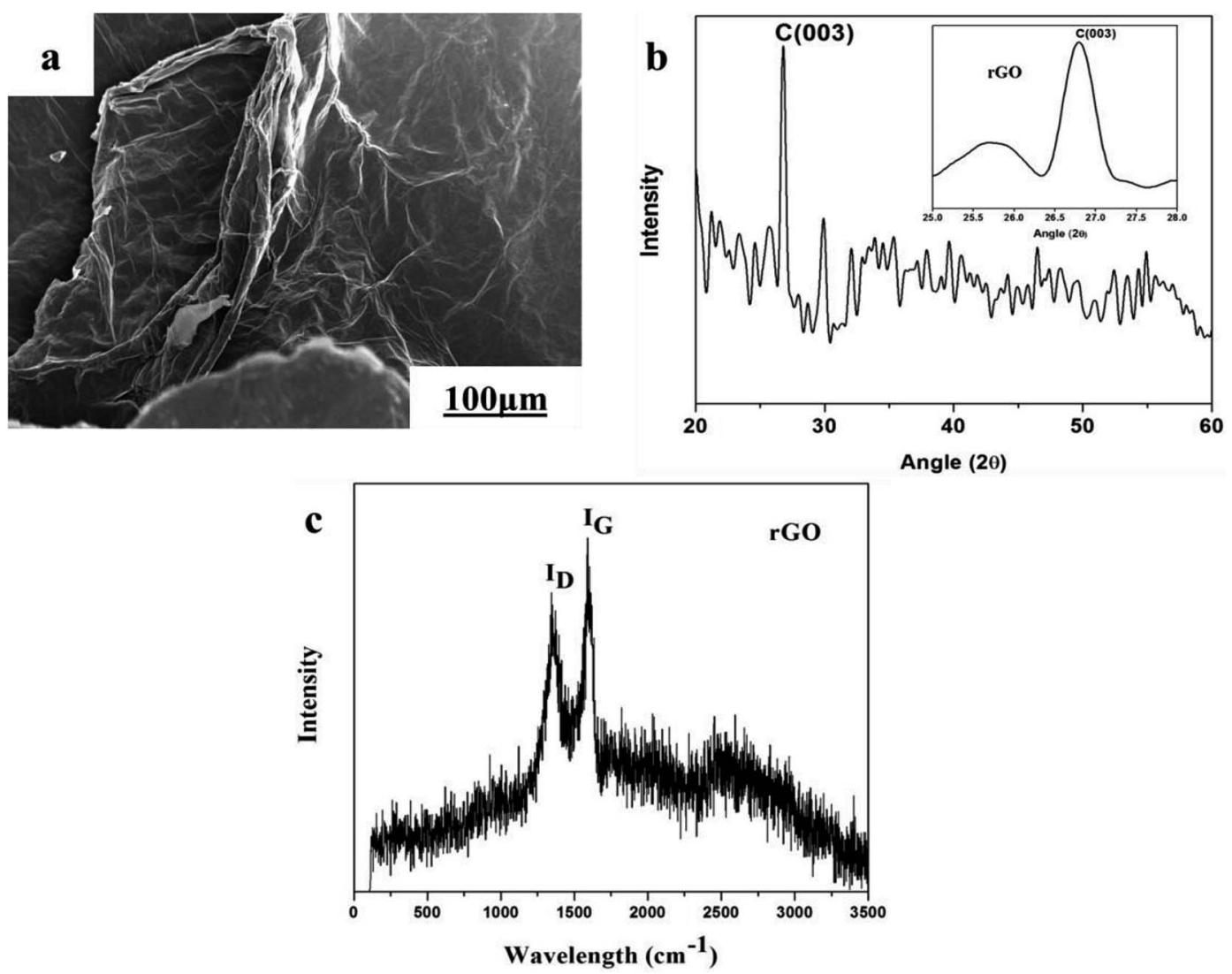

Fig. 4 Reduced graphene oxide powder: (a) SEM image, (b) XRD pattern and (c) Raman analysis.

rGO composites was not very strong and some voids are present, and the bonding inside rGO is also not strong enough and some voids were created and can be seen in Fig. 5. By increasing the amount of rGO within the $\mathrm{Cu}$ matrix, the size of the voids was enlarged, which can be seen clearly in the inset of Fig. $5 b-d$ and is highlighted by the arrows, while the presence of rGO can also be observed clearly and is highlighted by arrows. This is due to the relatively big difference between the density of $\mathrm{Cu}$ and $\mathrm{rGO}$ and poor wettability property of the Cu matrix. The density of the $\mathrm{Cu}$-rGO composites was observed to be lower due to the occurrence of these voids. At a low concentration of rGO, the voids are very few, but by increasing the amount of rGO, voids inside $\mathrm{rGO}$ and between $\mathrm{Cu}$ and $\mathrm{rGO}$ in the composites were seen clearly and the bending of rGO was also prominent. The presence of these voids may have a negative effect on the thermal properties of the composites. A SEM image of the pure $\mathrm{Cu}$ matrix after sintering can be seen in Fig. 5a for comparison with the $\mathrm{Cu}-\mathrm{rGO}$ composites. The same problem occurred between the pure $\mathrm{Cu}$ matrix layers; interfacial bonding between two layers is not strong enough and some voids were clearly observed. Mostly, voids appeared between the interfaces of $\mathrm{Cu}$ and rGO. But, it can be seen from Fig. 5 that rGO is highly aligned and well-ordered within the $\mathrm{Cu}$ matrix with a little bending occurring due to the pressure applied during the sintering process. This will be beneficial for the improvement of anisotropic thermal conductivity.

\subsection{High anisotropic thermal conductivity of $\mathrm{Cu}-\mathrm{rGO}$ composites}

The thermal conductivity (TC) values of the composites in-plane $\left(K_{\|}\right)$were 4-9 times greater than the through-plane $\left(K_{\perp}\right)$ values for different concentrations of rGO, due to the higher degree of alignment of rGO in the composites. By increasing the amount of $\mathrm{rGO}$ in the composites, the ratio between in-plane and through-plane TC was increased significantly. The maximum in-plane thermal conductivity for the $\mathrm{Cu}-\mathrm{rGO}$ composites was observed when using 0.6 vol\% $\mathrm{rGO}$. The reason is that the density of $0.6 \mathrm{vol} \% \mathrm{Cu}-\mathrm{rGO}$ is $7.3644 \mathrm{~g} \mathrm{~cm}^{-3}$, which is relatively higher than that of the 0.4 and 0.8 vol\% $\mathrm{Cu}-\mathrm{rGO}$ composites, 6.3831 and $7.2825 \mathrm{~g} \mathrm{~cm}^{-3}$, respectively. However, the in-plane TC of $\mathrm{Cu}-\mathrm{rGO}$ decreased upon increasing the amount of rGO and it was less than even pure $\mathrm{Cu}$. The decreased value of TC is due to several reasons. Interfacial bonding between $\mathrm{Cu}$ and $\mathrm{rGO}$ was not strong and there are some voids present between them due to the poor wettability property of the $\mathrm{Cu}$ matrix, which causes the lower values of TC. Another reason is that there is some amount of oxygen also present in the interface region of the $\mathrm{Cu}-\mathrm{rGO}$ composites, which produced lattice phonon dissipation. The presence of oxygen causes a decrease in thermal interfacial conductance and deterioration of the TC; a similar effect was observed for the functionalization of CNTs in CNT$\mathrm{Cu}$ composites. ${ }^{37}$ Due to the large thermal expansion mismatch and poor adherence between $\mathrm{Cu}$ and $\mathrm{rGO}$, the interfacial 

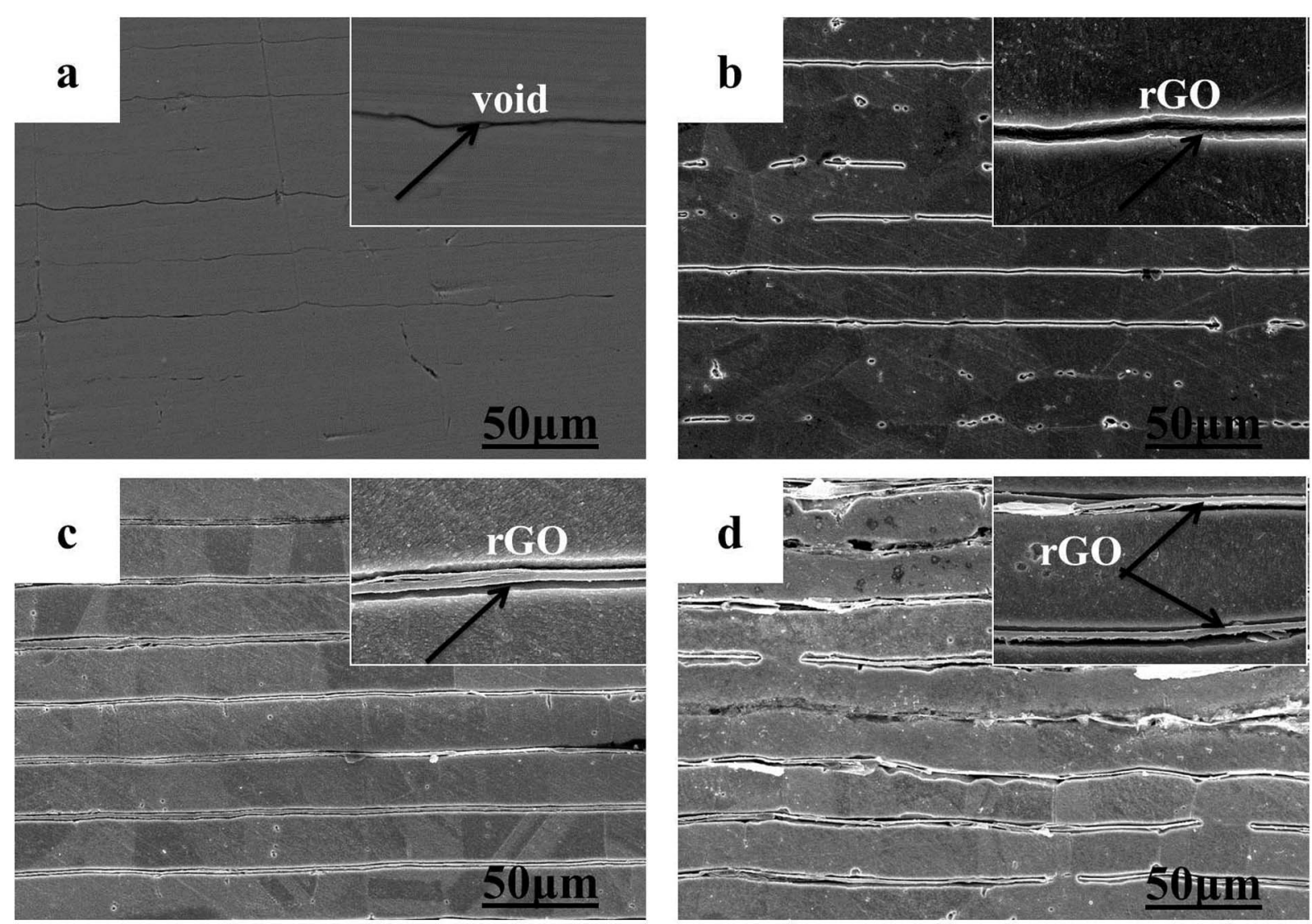

Fig. 5 Cross-sectional SEM images of pure Cu and Cu-rGO composites (b-d): (a) pure Cu substrate and (b) 0.4 vol\% rGO, (c) 0.6 vol\% rGO, and (d) 0.8 vol\% rGO (all inset figures show zoomed-in images).

thermal resistance was raised. However, compared with other fillers used to form composites with $\mathrm{Cu}$, the values of in-plane $\mathrm{TC}$ of the $\mathrm{Cu}-\mathrm{rGO}$ composites are much better. In spite of this, the anisotropic TC ratio increased significantly (8.82) at a very low concentration of rGO $(0.8 \mathrm{vol} \%)$ due to the higher degree of alignment of rGO, which was achieved by using a novel method for the fabrication of $\mathrm{Cu}-\mathrm{rGO}$ composites, as shown in Fig. 6 (inset). Furthermore, rGO has a very high value of in-plane TC, hundreds of times better than that throughplane, and for the composites, with a low concentration of $\mathrm{rGO}$, there is no literature available to the best of our knowledge to explain such a high difference between the in-plane and through-plane TC values. The fabrication method of the $\mathrm{Cu}-$ rGO composites used in this work is most suitable to get a higher anisotropic TC ratio.

\subsection{Laser test}

Laser test was done to verify the highly anisotropic structure of our best $\mathrm{Cu}-\mathrm{rGO}$ composite ( 0.8 vol\% rGO) sample and verify the heat dissipation property of the composite compared with pure $\mathrm{Cu}$. Laser was irradiated on the pure $\mathrm{Cu}$ and $\mathrm{Cu}-\mathrm{rGO}$ composite samples, as shown in Fig. 7. The power density of laser was set at $1000 \mathrm{~W} \mathrm{~cm}^{-2}$ and irradiation time was $5 \mathrm{~s}$. After the laser was irradiated on the samples, we measured the back surface temperature of our samples with the help of a thermocouple. Our 0.8 vol\% $\mathrm{Cu}-\mathrm{rGO}$ composite sample exhibited a higher anisotropic thermal conductivity compared with pure $\mathrm{Cu}$. An interesting result was obtained that the back surface temperature of the $\mathrm{Cu}-\mathrm{rGO}$ composite was $120^{\circ} \mathrm{C}$ less than that of pure $\mathrm{Cu}$, as shown in Fig. $8,29.3 \%$ lower than that

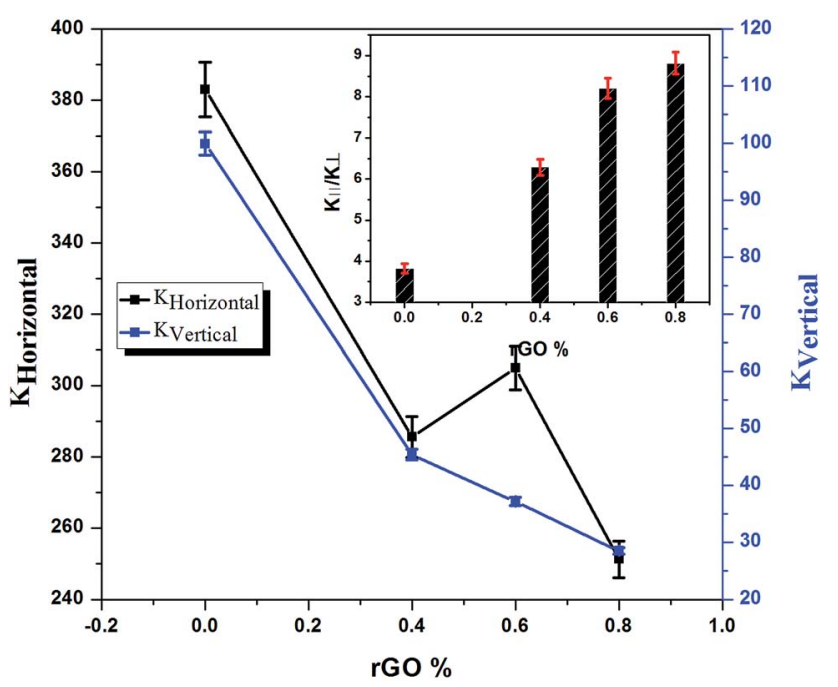

Fig. 6 The anisotropic thermal conductivity of the Cu-rGO composites. 


\section{(a) $\mathrm{Cu}$}

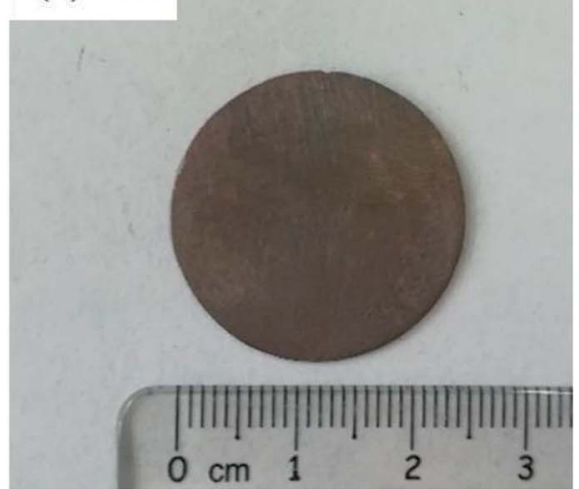

(b) Cu-rGO

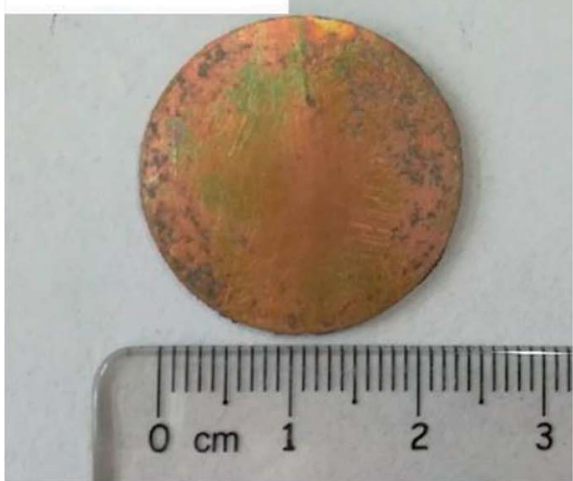

Fig. 7 Samples after laser irradiation: (a) pure Cu and (b) Cu-rGO (0.8 vol\% rGO).
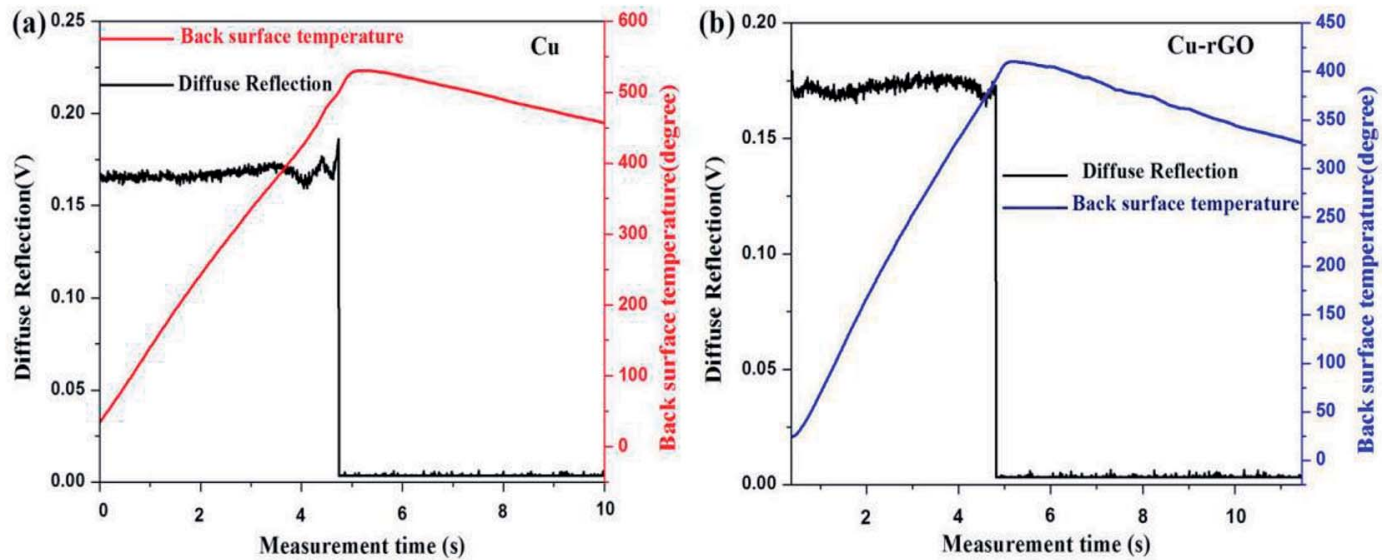

Fig. 8 Laser irradiation test data. Laser power: $1000 \mathrm{~W} \mathrm{~cm}^{-2}$; irradiation time: $5 \mathrm{~s}$. (a) Pure Cu. (b) Cu-rGO.

of pure $\mathrm{Cu}$. This is due to the large ratio between (horizontal) inplane $\left(251.23 \mathrm{~W} \mathrm{~m}^{-1} \mathrm{~K}^{-1}\right.$ ) and (vertical) through-plane $(28.48 \mathrm{~W}$ $\mathrm{m}^{-1} \mathrm{~K}^{-1}$ ) TC for the $\mathrm{Cu}-\mathrm{rGO}$ composite, 8.82 , and for $\mathrm{Cu}$, the ratio was 3 . This means that the large difference of anisotropic thermal conductivity values of $\mathrm{Cu}-\mathrm{rGO}$ plays an important role in heat dissipation. rGO was also highly aligned within the composite, which enables good heat dissipation, and the back surface temperature of the $\mathrm{Cu}-\mathrm{rGO}$ composite after laser irradiation was lower compared with pure $\mathrm{Cu}$.

\subsection{Flexural strength of $\mathrm{Cu}-\mathrm{rGO}$ composites}

The three point bending test was performed to investigate the flexural strength of pure sintered $\mathrm{Cu}$ and the $\mathrm{Cu}-\mathrm{rGO}$ composites, as shown in Fig. 9. The flexural strength of pure $\mathrm{Cu}$ was observed ( $99 \mathrm{MPa})$, while adding the rGO into the $\mathrm{Cu}$ matrix caused the flexural strength to firstly increase significantly and then decrease with increasing the concentration of rGO in the composites. At 0.4 and $0.6 \mathrm{vol} \% \mathrm{rGO}$ in the composites, the flexural strength was ascertained ( 121 and $127 \mathrm{MPa})$, being $18 \%$ and $22 \%$ higher than pure $\mathrm{Cu}$, respectively. With a low concentration of $\mathrm{rGO}$, the interfacial bonding between $\mathrm{Cu}$ and
rGO is better than at a higher concentration of $\mathrm{rGO}$, and the densities of the composites also show significant changes. At a higher concentration of $0.8 \mathrm{vol} \%$, the density of the composite

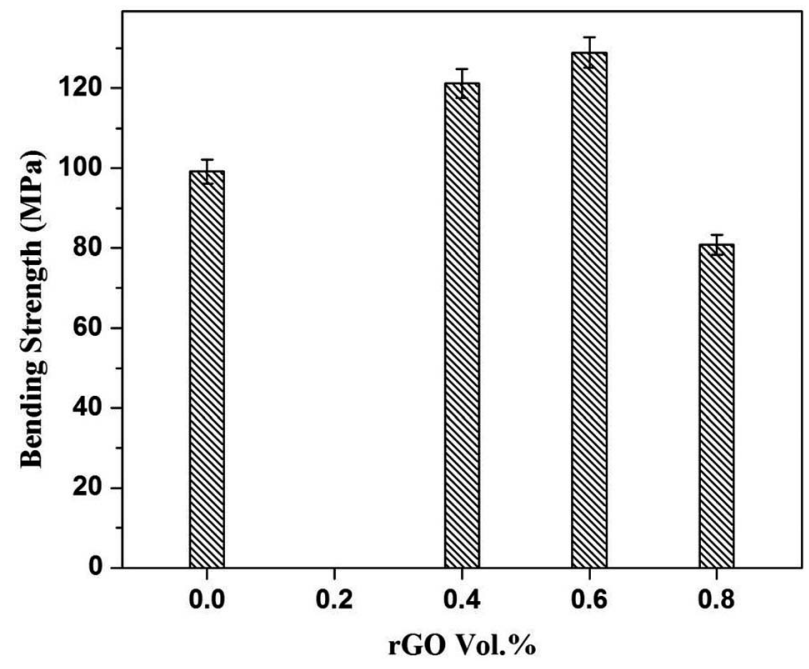

Fig. 9 Flexural strength of pure $\mathrm{Cu}$ and $\mathrm{Cu}-\mathrm{rGO}$ composites. 
is slightly lower compared with other composites due to the presence of voids, which also lead to a decrease in the flexural strength of the composites. The voids decrease the density as well as the mechanical properties of the composites, as has happened in our previous work.

\section{Conclusions}

In summary, $\mathrm{Cu}-\mathrm{rGO}$ composites were successfully fabricated by a simple and novel two step method of layer by layer selfassembly followed by hot press sintering. The most important advantage of this method is that rGO was highly aligned within the $\mathrm{Cu}$ matrix, while interfacial bonding between $\mathrm{Cu}$ and rGO was not so strong and voids can be seen in the interfacial area. But, due to the highly aligned rGO, we obtained highly anisotropic thermal conductivity values of the $\mathrm{Cu}-\mathrm{rGO}$ composites. Thermal conductivity in-plane $\left(251.23 \mathrm{~W} \mathrm{~m}^{-1} \mathrm{~K}^{-1}\right)$ and through-plane $\left(28.48 \mathrm{~W} \mathrm{~m}^{-1} \mathrm{~K}^{-1}\right)$ show the highest difference with a ratio of 8.82 . Laser irradiation tests also confirmed the good alignment of rGO in the $\mathrm{Cu}$ matrix and highly anisotropic behavior of the $\mathrm{Cu}-\mathrm{rGO}$ composites with a greater heat dissipation property. The value of back surface temperature $\left(330{ }^{\circ} \mathrm{C}\right)$ of the $\mathrm{Cu}-\mathrm{rGO}$ composite $(0.8$ vol\% rGO) was $29.3 \%$ less than that of pure $\mathrm{Cu}\left(450{ }^{\circ} \mathrm{C}\right)$. The flexural strength of the $\mathrm{Cu}-\mathrm{rGO}$ composites was also significantly increased compared with pure $\mathrm{Cu}$. At 0.6 vol\%, the flexural strength was ascertained to be $\sim 127 \mathrm{MPa}$, which is $22 \%$ higher than that of pure $\mathrm{Cu}$. A simple two-step facile fabrication method, involving highly aligned rGO and highly anisotropic thermal conductivity values with such a low percentage of rGO, was reported; this has not been observed before in the literature, to the best of our knowledge, to date. These composites may be used as heat sinks in thermal packaging systems and the electronics industry.

\section{Conflicts of interest}

There are no conflicts to declare.

\section{Acknowledgements}

The authors acknowledge the financial support of the National Natural Science Foundation of China (51772027). The authors are also very grateful to the Analytical and Testing Center of Beijing Normal University and the Chinese Academy physicochemical for providing experimental support.

\section{References}

1 M. Yang, L. Weng, H. Zhu, T. Fan and D. Zhang, Simultaneously enhancing the strength, ductility and conductivity of copper matrix composites with graphene nanoribbons, Carbon, 2017, 118, 250-260.

2 A. Simoncini, V. Tagliaferri and N. Ucciardello, High Thermal Conductivity of Copper Matrix Composite Coatings with Highly-Aligned Graphite Nanoplatelets, Materials, 2017, 10(11), 1226.
3 J. Renteria, S. Legedza, R. Salgado, M. P. Balandin, S. Ramirez, M. Saadah, F. Kargar and A. A. Balandin, Magnetically-functionalized self-aligning graphene fillers for high-efficiency thermal management applications, Mater. Des., 2015, 88, 214-221.

4 Q. Liu, X.-B. He, S.-B. Ren, C. Zhang, L. Ting-Ting and X.-H. Qu, Thermophysical properties and microstructure of graphite flake/copper composites processed by electroless copper coating, J. Alloys Compd., 2014, 587, 255-259.

5 J. Kováčik, Š. Emmer and J. Bielek, Thermal conductivity of Cu-graphite composites, Int. J. Therm. Sci., 2015, 90, 298-302. 6 J. Koráb, P. Štefánik, Š. Kavecký, P. Šebo and G. Korb, Thermal conductivity of unidirectional copper matrix carbon fibre composites, Composites, Part A, 2002, 33(4), 577-581.

7 E. Khaleghi, M. Torikachvili, M. A. Meyers and E. A. Olevsky, Magnetic enhancement of thermal conductivity in coppercarbon nanotube composites produced by electroless plating, freeze drying, and spark plasma sintering, Mater. Lett., 2012, 79, 256-258.

8 Z. Jia, T. Chen, J. Wang, J. Ni, H. Li and X. Shao, Synthesis, characterization and tribological properties of $\mathrm{Cu} /$ reduced graphene oxide composites, Tribol. Int., 2015, 88, 17-24.

9 P. Goli, H. Ning, X. Li, C. Y. Lu, K. S. Novoselov and A. A. Balandin, Thermal Properties of Graphene-CopperGraphene Heterogeneous Films, Nano Lett., 2014, 14(3), 1497-1503.

10 X. Gao, H. Yue, E. Guo, H. Zhang, X. Lin, L. Yao and B. Wang, Mechanical properties and thermal conductivity of graphene reinforced copper matrix composites, Powder Technol., 2016, 301, 601-607.

11 I. Firkowska, A. Boden, B. Boerner and S. Reich, The Origin of High Thermal Conductivity and Ultralow Thermal Expansion in Copper-Graphite Composites, Nano Lett., 2015, 15(7), 4745-4751.

12 K. Chu, X.-h. Wang, F. Wang, Y.-b. Li, D.-j. Huang, H. Liu, W.-l. Ma, F.-x. Liu and H. Zhang, Largely enhanced thermal conductivity of graphene/copper composites with highly aligned graphene network, Carbon, 2018, 127, 102112.

13 A. Boden, B. Boerner, P. Kusch, I. Firkowska and S. Reich, Nanoplatelet Size to Control the Alignment and Thermal Conductivity in Copper-Graphite Composites, Nano Lett., 2014, 14(6), 3640-3644.

14 K. Chu, X.-h. Wang, Y.-b. Li, D.-j. Huang, Z.-r. Geng, X.-l. Zhao, H. Liu and H. Zhang, Thermal properties of graphene/metal composites with aligned graphene, Mater. Des., 2018, 140, 85-94.

15 T. Wejrzanowski, M. Grybczuk, M. Chmielewski, K. Pietrzak, K. J. Kurzydlowski and A. Strojny-Nedza, Thermal conductivity of metal-graphene composites, Mater. Des., 2016, 99, 163-173.

16 A. A. Balandin, S. Ghosh, W. Bao, I. Calizo, D. Teweldebrhan, F. Miao and C. N. Lau, Superior Thermal Conductivity of Single-Layer Graphene, Nano Lett., 2008, 8(3), 902-907.

17 A. A. Balandin, Thermal properties of graphene and nanostructured carbon materials, Nat. Mater., 2011, 10, 569. 
18 S. F. Bartolucci, J. Paras, M. A. Rafiee, J. Rafiee, S. Lee, D. Kapoor and N. Koratkar, Graphene-aluminum nanocomposites, Mater. Sci. Eng., A, 2011, 528(27), 79337937.

19 L.-Y. Chen, H. Konishi, A. Fehrenbacher, C. Ma, J.-Q. Xu, H. Choi, H.-F. Xu, F. E. Pfefferkorn and X.-C. Li, Novel nanoprocessing route for bulk graphene nanoplatelets reinforced metal matrix nanocomposites, Scr. Mater., 2012, 67(1), 29-32.

20 M. Fang, K. Wang, H. Lu, Y. Yang and S. Nutt, Covalent polymer functionalization of graphene nanosheets and mechanical properties of composites, J. Mater. Chem., 2009, 19(38), 7098-7105.

21 C. He, N. Zhao, C. Shi, X. Du, J. Li, H. Li and Q. Cui, An Approach to Obtaining Homogeneously Dispersed Carbon Nanotubes in Al Powders for Preparing Reinforced Al-Matrix Composites, Adv. Mater., 2007, 19(8), 1128-1132.

22 S. S. Ho, P. K. Hyun, K. B. Hyun, C. Y. Won, J. G. Hoon, L. D. Ju, K. Byung-Seon, P. Kyung-Wook and J. Seokwoo, Enhanced Thermal Conductivity of Epoxy-Graphene Composites by Using Non-Oxidized Graphene Flakes with Non-Covalent Functionalization, Adv. Mater., 2013, 25(5), 732-737.

23 T. Kuilla, S. Bhadra, D. Yao, N. H. Kim, S. Bose and J. H. Lee, Recent advances in graphene based polymer composites, Prog. Polym. Sci., 2010, 35(11), 1350-1375.

24 F. Chen, J. Ying, Y. Wang, S. Du, Z. Liu and Q. Huang, Effects of graphene content on the microstructure and properties of copper matrix composites, Carbon, 2016, 96, 836-842.

25 M. Cao, D.-B. Xiong, Z. Tan, G. Ji, B. Amin-Ahmadi, Q. Guo, G. Fan, C. Guo, Z. Li and D. Zhang, Aligning graphene in bulk copper: Nacre-inspired nanolaminated architecture coupled with in situ processing for enhanced mechanical properties and high electrical conductivity, Carbon, 2017, 117, 65-74.

26 J. Hwang, T. Yoon, S. H. Jin, J. Lee, T. S. Kim, S. H. Hong and S. Jeon, Enhanced Mechanical Properties of Graphene/ Copper Nanocomposites Using a Molecular-Level Mixing Process, Adv. Mater., 2013, 25(46), 6724-6729.

27 L. Wang, Y. Cui, B. Li, S. Yang, R. Li, Z. Liu, R. Vajtai and W. Fei, High apparent strengthening efficiency for reduced graphene oxide in copper matrix composites produced by molecule-lever mixing and high-shear mixing, RSC Adv., 2015, 5(63), 51193-51200.

28 Y. Chen, X. Zhang, E. Liu, C. He, C. Shi, J. Li, P. Nash and N. Zhao, Fabrication of in situ grown graphene reinforced Cu matrix composites, Sci. Rep., 2016, 6, 19363.

29 Y. Chen, X. Zhang, E. Liu, C. He, Y. Han, Q. Li, P. Nash and N. Zhao, Fabrication of three-dimensional graphene/Cu composite by in situ CVD and its strengthening mechanism, J. Alloys Compd., 2016, 688, 69-76.

30 H. Cao, D.-B. Xiong, Z. Tan, G. Fan, Z. Li, Q. Guo, Y. Su, C. Guo and D. Zhang, Thermal properties of in situ grown graphene reinforced copper matrix laminated composites, J. Alloys Compd., 2019, 771, 228-237.

31 D.-B. Xiong, M. Cao, Q. Guo, Z. Tan, G. Fan, Z. Li and D. Zhang, Graphene-and-Copper Artificial Nacre Fabricated by a Preform Impregnation Process: Bioinspired Strategy for Strengthening-Toughening of Metal Matrix Composite, ACS Nano, 2015, 9(7), 6934-6943.

32 C. L. P. Pavithra, B. V. Sarada, K. V. Rajulapati, T. N. Rao and G. Sundararajan, A New Electrochemical Approach for the Synthesis of Copper-Graphene Nanocomposite Foils with High Hardness, Sci. Rep., 2014, 4, 4049.

33 K. Jagannadham, Thermal Conductivity of Copper-Graphene Composite Films Synthesized by Electrochemical Deposition with Exfoliated Graphene Platelets, Metall. Mater. Trans. B, 2012, 43(2), 316-324.

34 C.-C. Hsieh and W.-R. Liu, Synthesis and characterization of nitrogen-doped graphene nanosheets/copper composite film for thermal dissipation, Carbon, 2017, 118, 1-7.

35 F. Nazeer, Z. Ma, L. Gao, F. Wang, M. A. Khan and A. Malik, Thermal and mechanical properties of copper-graphite and copper-reduced graphene oxide composites, Composites, Part B, 2019, 163, 77-85.

36 P. M. Adams, H. A. Katzman, G. S. Rellick and G. W. Stupian, Characterization of high thermal conductivity carbon fibers and a self-reinforced graphite panel, Carbon, 1998, 36(3), 233-245.

37 K. J. Kim, J. H. Kim, T. H. Jung and S. W. Nam, Closed-form design of sharp FIR half-band filters, Hilbert transformer, and differentiator, 2011, IEEE 9th International New Circuits and systems conference, 2011, pp. 181-184. 